\title{
Caracterização física, química e fisiológica de gabiroba (Campomanesia pubescens) durante o desenvolvimento
}

\author{
Physical, chemical and physiological characterization of gabiroba fruit \\ (Campomanesia pubescens) during its development
}

\author{
Edson Pablo da SILVA ${ }^{1 *}$, Eduardo Valério de Barros VILAS BOAS ${ }^{1}$, \\ Luiz Jorge RODRIGUES ${ }^{1}$, Heloisa Helena SIQUEIRA ${ }^{1}$
}

\section{Resumo}

O objetivo deste trabalho foi caracterizar a gabiroba (Campomanesia pubescens) ao longo do seu desenvolvimento por meio de análises físicas, químicas e fisiológicas. Os frutos foram coletados a $8 \mathrm{~km}$ de Lavras, sul de Minas Gerais, em intervalos de 5 dias, a partir da antese até a sua maturação completa. A floração da gabiroba iniciou-se no mês de agosto e o ápice do evento foi no mês de setembro; sua frutificação inicial ocorreu no mês de setembro, sendo outubro o período ideal para coleta. O período compreendido entre a abertura da flor (antese) e o amadurecimento foi de 63 dias (9 semanas). O fruto atingiu o tamanho máximo aos 63 dias ( $9^{\text {a }}$ semana) após a antese, com 4,26 g, 17,39 mm e 16,03 mm, representando a sua massa, os diâmetros transversal e longitudinal, respectivamente. A gabiroba apresentou um incremento nos valores de massa, diâmetros transversal e longitudinal, valores $\mathrm{L}^{*}$ e $\mathrm{a}^{\star}$, vitamina $\mathrm{C}$, açúcares totais, sólidos solúveis (SS) e pectina solúvel com o decorrer do desenvolvimento do fruto, seguindo um padrão sigmoidal simples. Observou-se redução na taxa respiratória e atividade de poligalacturonase entre 48 e 53 dias, além de redução na firmeza e clorofila total e oscilação do valor b e pectina total ao longo do desenvolvimento.

Palavras-chave: frutos do cerrado; crescimento; maturação.

\begin{abstract}
The objective of this work was to characterize the gabiroba fruit (Campomanesia pubescens) during its development through physical, chemical, and biochemical analyses. The fruits were harvested $8 \mathrm{~km}$ off the city of Lavras, south of Minas Gerais, Brazil every 5 days from anthesis until complete maturation. The flowering of the gabiroba started in August and its maximum was in September, when the early fructification occurred although October is the ideal period to harvest. The period between flowers opening (anthesis) until ripening lasted 63 days ( 9 weeks). The fruit reached its maximum size at 63 days ( $9^{\text {th }}$ week) after anthesis, with 4,26 g, 17,39 mm and 16,03 mm, representing its mass and longitudinal and transversal diameters, respectively. The gabiroba fruit presented a significant increase of mass, longitudinal and transversal diameters, $\mathrm{L}^{*}$ and $\mathrm{a}^{*}$ values, vitamin $\mathrm{C}$, total sugar, soluble solids and soluble pectin, during its development showing a simple sigmoidal behaviour. It was observed a decrease in the respiration rate and polygalacturonase activity between 48 and 53 days, as well as reduction in the firmness, total chlorophyll, and oscillation in the $b^{*}$ value and total pectin during the development of the fruit.
\end{abstract}

Keywords: savanna fruit; growth; maturation.

\section{Introdução}

O cerrado constitui grande fonte natural de recursos biológicos. Ocupa aproximadamente $22 \%$ do território nacional, dos quais, cerca de $90 \%$ estão situados nos Estados de São Paulo, Minas Gerais, Mato Grosso, Goiás e Bahia (FONSECA; MUNIZ, 1992). Esse bioma é considerado o segundo maior do País, superado apenas pela Floresta Amazônica (RIBEIRO; WALTTER, 1998).

Existem poucos estudos sobre desenvolvimento de espécies nativas do cerrado, não havendo, portanto, o conhecimento das etapas de crescimento, pré-maturação, maturação, amadurecimento e senescência.

O estudo do desenvolvimento é importante para o estabelecimento do ponto ideal de colheita e para a aplicação de tecnologias que retardem ou reduzam as atividades fisiológicas, aumentando seu período de conservação (CHITARRA, 1998; VILAS BOAS, 1999).

Os desafios para a exploração dos frutos nativos existem; em contraposição, há um grande potencial a ser buscado, principalmente para a sua exportação, já que possuem sabores sui generis e não são encontrados em outros países (ALMEIDA et al., 1998).

O conhecimento a respeito da planta é importante para sua inserção no mercado consumidor, preservação em seu estado natural e implantação de futuras lavouras comerciais. Entretanto, não há estudos inerentes à gabirobeira, em especial a seus frutos após a colheita.

${ }^{1}$ Ciência dos Alimentos, Universidade Federal de Lavras - UFL, CEP 37200-000, Lavras - MG, Brasil, E-mail: edsonpablos@hotmail.com

${ }^{*}$ A quem a correspondência deve ser enviada 
Campomanesia pubescens (Berg), denominada de gabiroba é um arbusto que pode atingir $60-80 \mathrm{~cm}$ de altura e normalmente ocorre em moitas, e sua frutificação dá-se de setembro a outubro. Como outras espécies pertencentes à família Myrtaceae, apresenta frutos de sabor adocicado, podendo sua polpa ser consumida in natura ou na forma de sucos ou geleias.

O presente estudo teve como objetivos a caracterização física, química e fisiológica da gabiroba (Campomanesia pubescens), ao longo do seu desenvolvimento, incluindo amadurecimento. Essa caracterização visa o melhor entendimento do comportamento pré e pós-colheita do fruto, o que poderá servir de base na adoção de técnicas adequadas de produção e conservação, minimizando perdas.

\section{Material e métodos}

O trabalho foi conduzido durante os meses de julho de 2007 a dezembro de 2007, em uma área de pastagem nativa com formação típica do cerrado e com predomínio da espécie Campomanesia pubescens localizada a $8 \mathrm{~km}$ do município de Lavras, sul do Estado de Minas Gerais.

Foram selecionados ao acaso cerca de 120 exemplares da espécie, homogêneos quanto ao porte, nos quais foram marcadas as flores por ocasião da antese, com fios de lã de diferentes cores. Imediatamente após a formação dos frutos, foram colhidos 600 frutos fracionados em quatro lotes iguais, representando as repetições. Com o crescimento dos frutos, a quantidade coletada foi diminuída, sendo cada repetição constituída de 120 unidades.

Em intervalos de 5 dias, a contar da sua formação, os frutos foram colhidos pela manhã, acondicionados em sacos de polietileno e transportados para o Laboratório de Pós-colheita de Frutas e Hortaliças do Departamento de Ciência dos Alimentos da Universidade Federal de Lavras.

O período total de coleta prolongou-se até que os frutos, ainda nos arbustos, atingiram o amadurecimento, caracterizado quando a casca apresentou a cor amarela.

$\mathrm{Na}$ chegada ao laboratório, os frutos sadios foram avaliados quanto à firmeza $(\mathrm{N})$ e cor $\left(\mathrm{L}^{*}, \mathrm{a}^{*} \mathrm{eb}^{*}\right)$, foram pesados e medidos seus diâmetros longitudinal e transversal.

Em seguida, foram congelados com o auxílio de nitrogênio líquido e armazenados a $-80^{\circ} \mathrm{C}$ para análises físicas, químicas e fisiológicas.

\subsection{Análises}

\section{Massa, diâmetro longitudinal e diâmetro transversal}

A massa foi avaliada em uma balança semianalítica Mettler, modelo PC 2000 e os resultados, expressos em gramas (g).

Para se obter os diâmetros longitudinal e transversal, o fruto foi medido com o auxílio de um paquímetro nos dois sentidos, e os resultados expressos em milímetros ( $\mathrm{mm}$ ).

\section{Coloração}

A coloração foi determinada em três pontos distintos da casca e polpa dos frutos, utilizando-se o colorímetro Minolta CR-400, com a determinação no modo CIE L*a* ${ }^{\star} b^{*}$. A coordenada $L^{\star}$ representa quão clara ou escura é a amostra, com valores variando de 0 (totalmente preta) a 100 (totalmente branca); a coordenada $\mathrm{a}^{*}$ pode assumir valores de $-80 \mathrm{a}+100$, em que os extremos correspondem ao verde e ao vermelho, respectivamente; a coordenada $b^{*}$, com a intensidade de azul ao amarelo, pode variar de -50 (totalmente azul) a +70 (totalmente amarelo).

\section{Clorofila total}

Foi determinada em $1 \mathrm{~g}$ de casca fresca triturada em $10 \mathrm{~mL}$ de água, com auxílio de homogeneizador de tecidos. $\mathrm{O}$ extrato foi transferido para um balão volumétrico de $50 \mathrm{~mL}$, completando-se o volume com acetona. Após um período de repouso no escuro, realizou-se a filtração. A leitura da absorbância do extrato foi efetuada a $652 \mathrm{~nm}$ e os resultados expressos em mg. $100 \mathrm{~g}^{-1}$ de casca fresca. Esta foi calculada utilizando-se a equação adotada por Engel e Poggiani (1991).

\section{Firmeza}

A firmeza foi determinada com o auxílio de um texturômetro Stable Micro System modelo TATX2i, utilizando a sonda tipo agulha $\mathrm{P} / 2 \mathrm{~N}$ ( $2 \mathrm{~mm}$ de diâmetro), que media a força de penetração desta nos frutos, numa velocidade de $5 \mathrm{~mm} / \mathrm{s}$ e a uma distância de penetração de $5 \mathrm{~mm}$, valores estes previamente fixados. Foi usada uma plataforma HDP/90 como base. A firmeza da gabiroba foi expressa em Newton (N).

\section{Taxa respiratória}

Recipientes de plástico de $50 \mathrm{~mL}$ contendo aproximadamente $5 \mathrm{~g}$ de frutos foram fechados por 1 hora, com tampa plástica, contendo um septo de silicone, por onde eram retiradas alíquotas da amostra interna, com o auxílio do analisador de gases PBI Dansensor. Os resultados, expressos em \% de $\mathrm{CO}_{2}$, foram convertidos em $\mathrm{mL}$. $\mathrm{CO}_{2} \mathrm{~kg}^{-1} \cdot \mathrm{h}^{-1}$, levando-se em consideração o volume de recipiente, a massa e o volume dos frutos em cada recipiente e o tempo que esse mesmo recipiente permaneceu fechado.

\section{pH e acidez titulável (AT)}

$\mathrm{O} \mathrm{pH}$ foi determinado utilizando-se um pHmetro Schott Handylab, segundo técnica da AOAC (1990). A determinação da acidez titulável foi realizada por titulação com solução de hidróxido de sódio $(\mathrm{NaOH}) 0,1 \mathrm{~N}$, usando como indicador a fenolftaleína, de acordo com o Instituto Adolfo Lutz (1985). Os resultados foram expressos em porcentagem de ácido cítrico.

\section{Sólidos solúveis totais (SST)}

Os sólidos solúveis totais foram determinados por refratometria, e foi utilizado o refratômetro digital ATAGO PR-100 com compensação de temperatura automática a $25^{\circ} \mathrm{C}$ 
e os resultados foram expressos em ${ }^{\circ} \mathrm{Brix}$, conforme a AOAC (1990).

\section{Vitamina C}

O teor de ácido ascórbico (após a oxidação a ácido dehidroascórbico) foi determinado pelo método colorimétrico, utilizando-se 2,4 de dinitrofenilhidrazina, segundo Strohecker e Henning (1967). Os resultados foram expressos em mg de ácido ascórbico por $100 \mathrm{~g}$ de polpa.

\section{Pectinas total e solúvel}

Foram extraídas de acordo com a técnica de McCready e McColomb (1952) e determinadas, espectrofotometricamente, a $520 \mathrm{~nm}$, segundo técnica de Blumenkrantz e Asboe-Hansen (1973). Os resultados foram expressos em $\mathrm{mg}$ de ácido galacturônico por $100 \mathrm{~g}$ de polpa.

\section{Pectinametilesterase (PME)}

A extração enzimática foi realizada segundo técnica de Buecher e Furmanski (1978), com modificações (VILAS BOAS, 1995). A determinação da atividade da PME seguiu as técnicas de Hultin et al. (1966) e Ratner (1969), com modificações (VILAS BOAS, 1995). Uma unidade de PME foi definida como a quantidade de enzima capaz de catalisar a desmetilação de pectina correspondente ao consumo de $1 \eta \mathrm{mol}$ de $\mathrm{NaOH}$ por grama de polpa fresca.min.

\section{Poligalacturonase $(P G)$}

A extração da enzima PG foi realizada segundo a técnica de Buescher e Furmanski (1978), com modificações de Vilas Boas (1995). O doseamento foi realizado segundo Markovic et al. (1975), com modificações de Vilas Boas (1995). A atividade enzimática foi expressa em $\eta$ mol de ácido galacturônico por grama de polpa por minuto.

\section{Análise estatística}

As análises estatísticas das variáveis físicas, fisiológicas e químicas foram realizadas com o auxílio do programa SISVAR (FERREIRA, 2000). Após a análise de variância dos resultados obtidos, observou-se o nível de significância do teste $F$. As médias dos períodos (semanas) de avaliação foram submetidas à regressão polinomial, em que os modelos são selecionados de acordo com a significância do teste $F$ de cada modelo e com o coeficiente de determinação.

\section{Delineamento experimental}

O experimento foi conduzido em delineamento inteiramente casualizado (DIC). Os tratamentos foram dispostos por um fatorial simples, sendo constituídos por onze períodos (semanas) de avaliações com quatro repetições.

\section{Resultados e discussão}

A floração da gabiroba no município de Lavras, sul do Estado mineiro, iniciou-se em agosto de 2006. O ápice desse evento ocorreu no mês de setembro, quando também foi observada a frutificação inicial, com o pico no mês de outubro.

O estádio de desenvolvimento compreendeu 63 dias e foi considerado a partir da abertura da flor (antese), até a colheita, definida quando os frutos apresentavam uma facilidade para serem destacados dos arbustos e apresentavam cor verde amarelada. O intervalo entre a antese e o amadurecimento varia em diferentes espécies de frutos (MARTINS et al., 2003; MOURA et al., 2004). O estádio de desenvolvimento dos frutos inicia-se, normalmente, com a fertilização, que é seguida por etapas, como formação, crescimento e maturação, incluindo a fase de amadurecimento e senescência (CHITARRA; CHITARRA, 2005).

A formação e o crescimento da gabiroba iniciaram-se com a polinização e fertilização da flor, sendo os primeiros frutilhos colhidos 13 dias após a abertura da flor (antese). O desenvolvimento estendeu-se até os 63 dias, último ponto observado. Chitarra e Chitarra (2005) relatam que alguns hormônios podem estar envolvidos no crescimento do fruto, sendo as auxinas os principais responsáveis. As auxinas participam ativamente do crescimento das células do fruto, estando relacionadas positivamente com tamanho e forma final. A formação e o crescimento representam a primeira fase na vida de um fruto, normalmente resultantes de rápido crescimento do ovário, que usualmente se segue à polinização e fertilização (HULME, 1970).

Durante os 63 dias de desenvolvimento $(\mathrm{p}<0,01)$, observouse aumento significativo de massa e diâmetros longitudinal e transversal da gabiroba (Figuras 1a, b, c). Com base na Figura 1, sugere-se um comportamento sigmoidal simples de crescimento para a gabiroba. Tal observação é coerente com os resultados de Santos et al. (2005), que avaliaram o desenvolvimento e maturação de abacaxi Smooth cayenne.

Observou-se redução na taxa respiratória da gabiroba ao longo do desenvolvimento, com base na equação de regressão utilizada no ajuste dos dados. Entretanto, um nítido comportamento climatérico foi observado, considerando-se os dados observados entre o $43^{\circ}$ e $53^{\circ}$ dias como sendo o pico climatérico respiratório observado aos 48 dias (Figura 2).

Após a colheita de qualquer parte do vegetal, a respiração torna-se o seu principal processo fisiológico, uma vez que não depende mais da absorção de água e minerais efetuados pelas raízes, da condução de nutriente pelo sistema vascular, nem da atividade fotossintetizante das folhas da planta-mãe. Portanto, as partes do vegetal adquirem vida independente e utilizam, para tal, suas próprias reservas metabólicas acumuladas nas fases de crescimento e de maturação (CHITARRA; CHITARRA, 2005).

A partir do $43^{\circ}$ dia, foi observada nas gabirobas elevação de sólidos solúveis (SS) e $\mathrm{pH}$ e, a partir do $48^{\circ}$ dia, redução da acidez titulável (AT) (Figura 3), período coincidente com o climatério respiratório dos frutos, o que reforça a hipótese da 

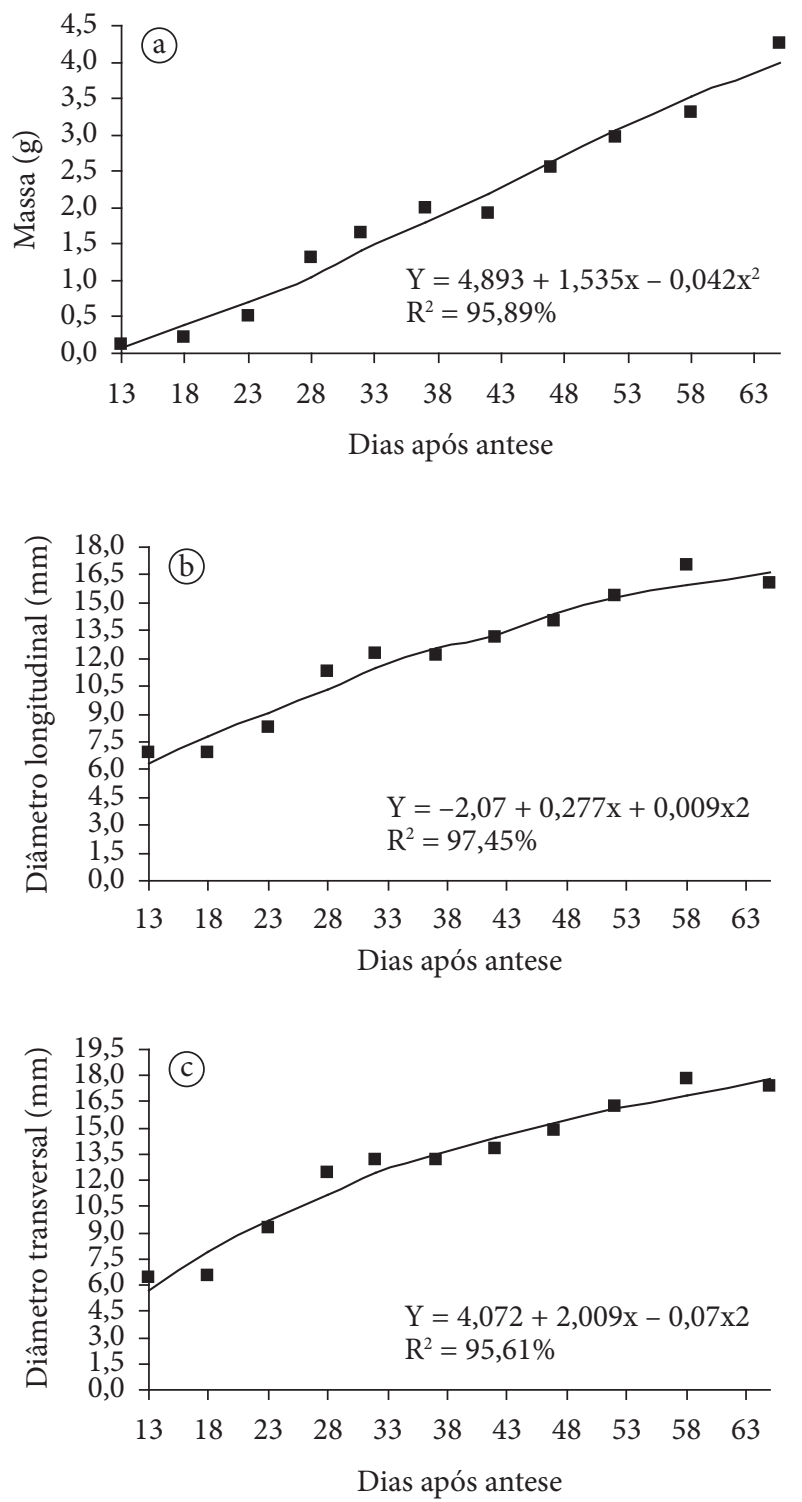

Figura 1. a, b e c) valores médios de massa (g), diâmetro longitudinal $(\mathrm{mm})$ e diâmetro transversal $(\mathrm{mm})$ de gabiroba.

gabiroba como fruto climatérico e este como sendo o estádio de amadurecimento dos frutos.

As análises químicas de $\mathrm{pH}$, ATT e SS são comumente realizadas para a maioria das frutas, pois estas estão diretamente ligadas ao sabor apresentado. As concentrações apresentadas podem influenciar a sua aceitação perante o consumidor.

Chitarra e Chitarra (2005) relatam que, com o amadurecimento, as frutas perdem rapidamente a acidez, mas, em alguns casos, há um pequeno aumento nos valores com o avanço da maturação. Esta pode ser utilizada em conjunto com a doçura, como ponto de referência do grau de maturação.

Para os valores de vitamina $C$, foi observado um incremento em sua concentração a partir de 33 dias após a antese e queda entre 53 e 63 dias, período entendido como final

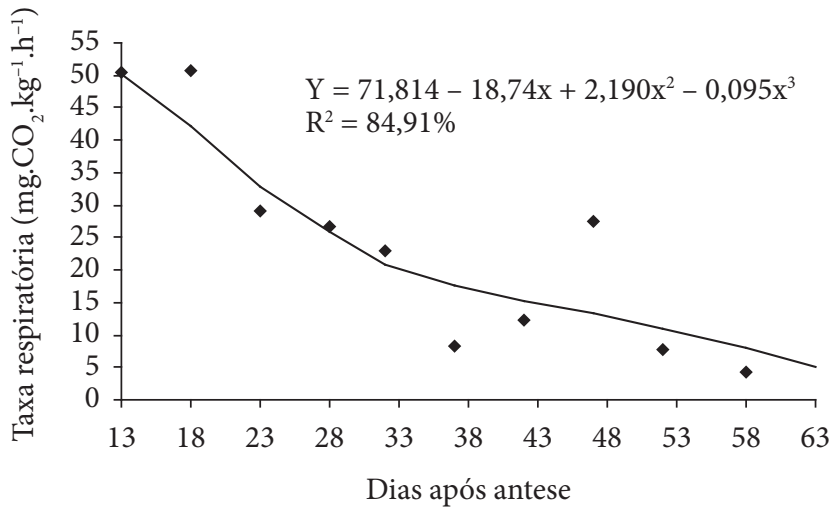

Figura 2. Valores médios para a taxa respiratória dos frutos de gabiroba.

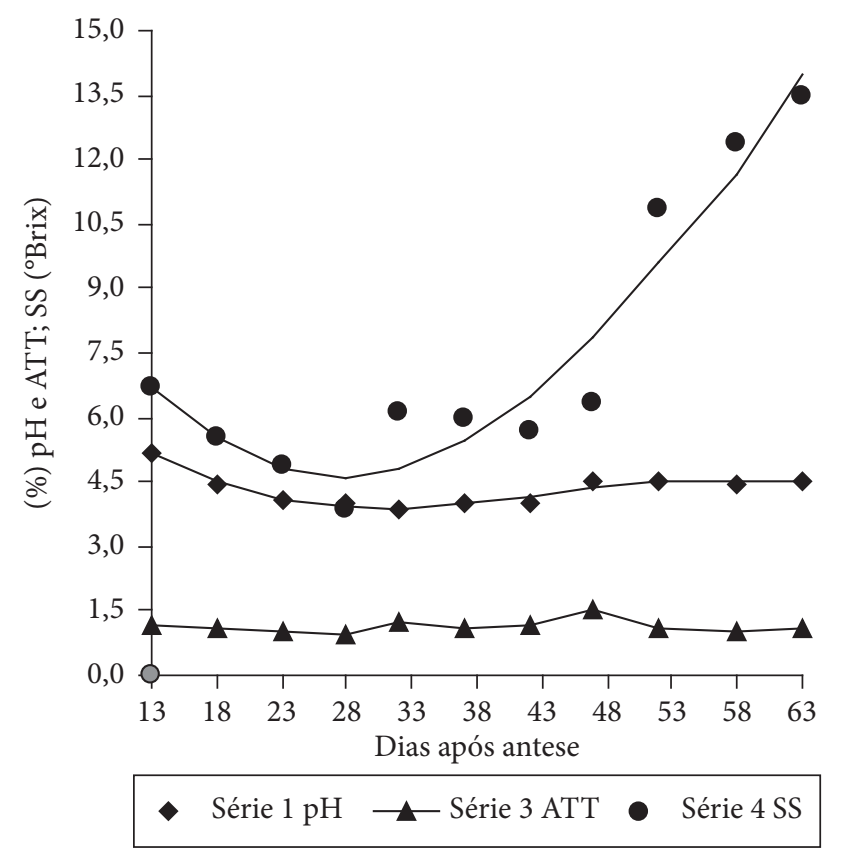

Figura 3. Valores de $\mathrm{pH}, \mathrm{ATT}(\%)$ eSS ( $\left.{ }^{\circ} \mathrm{Brix}\right)$, durante o desenvolvimento da gabiroba.

do amadurecimento e início da senescência. Ao final do amadurecimento e início da senescência, os frutos apresentaram aproximadamente $0,6 \%$ de vitamina $C$, um teor extremamente considerável em comparação com outras frutíferas como goiaba, laranja, limão, dentre outras.

O teor de ácido ascórbico pode ser utilizado como um índice de qualidade dos alimentos, porque varia no produto de acordo com as condições de cultivo, armazenamento e processamento (CHITARRA; CHITARRA, 2005).

Foram observadas alterações na coloração da casca da gabiroba $(\mathrm{p}<0,05)$, evidenciadas por meio das coordenadas $\mathrm{L}^{*}, \mathrm{a}^{*} \mathrm{e} \mathrm{b}^{*}$. Os valores $\mathrm{L}^{*} \mathrm{e} \mathrm{a}^{*}$ apresentaram comportamento quadrático com o desenvolvimento do fruto (Figuras $5 \mathrm{a}, \mathrm{b}$ ). A relação entre estes dois parâmetros indica a perda da intensidade 


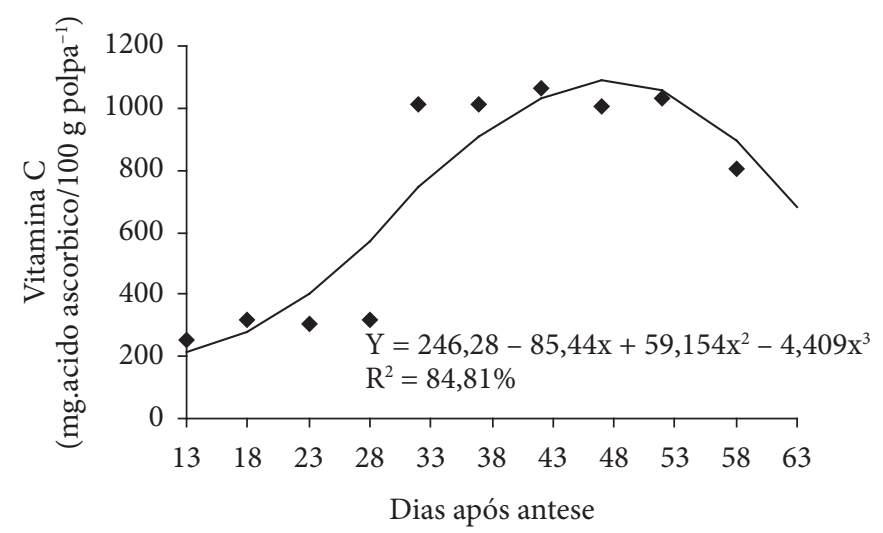

Figura 4. Valores médios de vitamina $\mathrm{C}$ durante o desenvolvimento da gabiroba.

da cor verde com o crescimento do fruto, mudando de verdeescuro $\left(\mathrm{L}^{*}=4,65 \mathrm{e} \mathrm{a}^{*}=-24,82\right)$ para verde claro $\left(\mathrm{L}^{*}=36,80\right.$ e $\left.\mathrm{a}^{*}=-5,86\right)$. Entre os dias 48 e 53 pode-se observar um aumento no valor $\mathrm{b}^{\star}$, indicando o amarelecimento do fruto (Figura 5c).

A variável clorofila total apresentou queda em sua concentração, durante o desenvolvimento do fruto. Comparando os resultados obtidos de clorofila total e valor $\mathrm{a}^{*}$, nota-se um comportamento inverso que indica perda da coloração verde da casca do fruto resultante do processo de degradação de clorofila (Figura 6). Tem-se como certo que a coloração verde dos vegetais se deve à presença de clorofila, e que o desverdecimento está associado com a sua degradação. Durante a maturação das frutas, os cloroplastos e suas membranas tilacoides se desintegram, ocorrendo perda rápida da clorofila e da cor verde dos tecidos. Vários fatores podem atuar isoladamente ou em conjunto, dentre eles, o pH, influenciado pelo acúmulo de ácidos orgânicos nos vacúolos, sistemas oxidativos e clorofilases (CHITARRA; CHITARRA, 1990; CHITARRA; CHITARRA, 2006).

Vale salientar que as mais intensas modificações associadas à coloração dos frutos ocorreram, mais uma vez, a partir do início do climatério respiratório.

A firmeza do fruto oscilou durante o seu desenvolvimento, podendo ter sido influenciada pela disponibilidade de água e luz absorvida do meio. O alto valor observado aos 18 dias provavelmente foi influenciado pelo processo de formação das sementes, onde a sonda encontrou maior resistência devido à presença destas. A partir dos 48 dias a firmeza tendeu a diminuir, indicando o amaciamento e amadurecimento do fruto (Figura 7a).

Rodrigues (2005) reportou resultados semelhantes com o pequi (Caryocar brasiliense), fruto nativo do cerrado, observando um decréscimo linear na firmeza. A firmeza está relacionada com a força necessária para que o produto atinja uma dada deformação, dando uma ideia das transformações na estrutura celular, da coesão das células e das alterações bioquímicas (CHITARRA; CHITARRA, 2005).
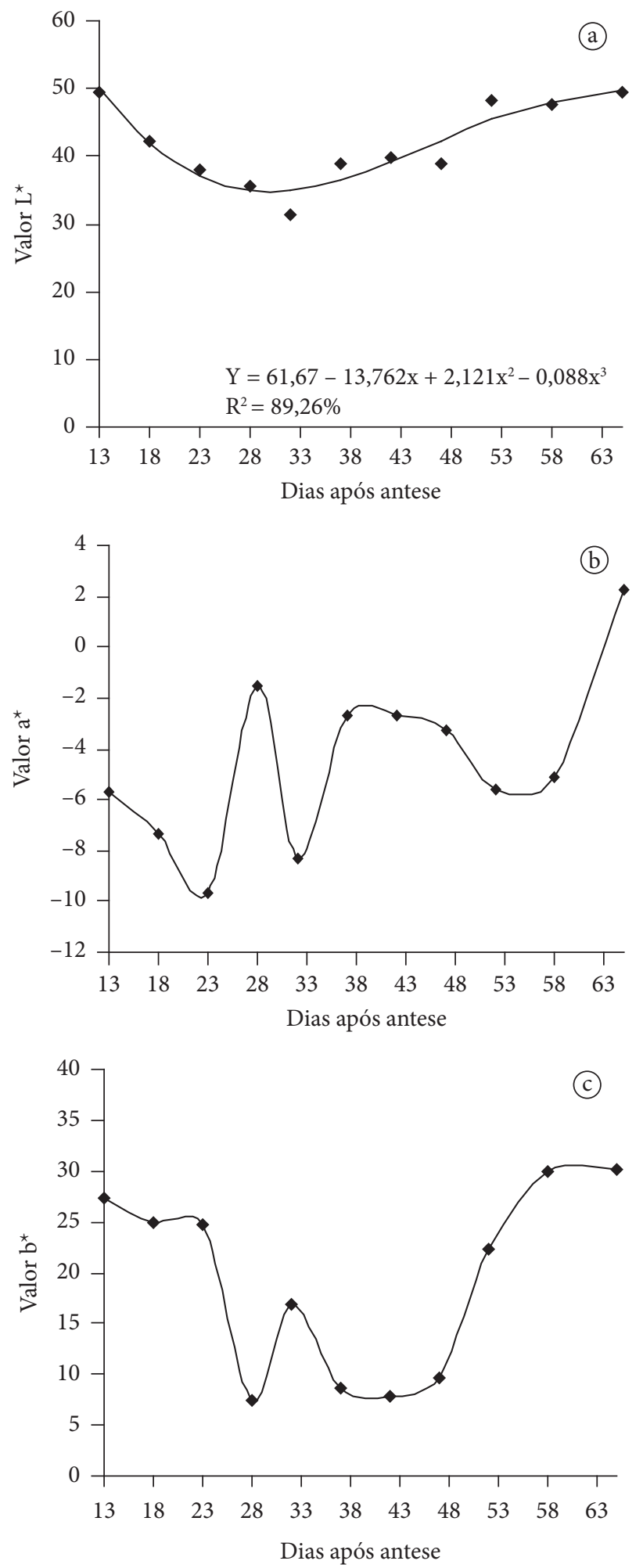

Figura 5. a, b) Valores médios de $\mathrm{L}^{\star} \mathrm{e} \mathrm{a}^{\star}$ de gabiroba; e c) valores médios para a medida de cor valor $b^{\star} e m$ frutos de gabiroba.

Observou-se grande oscilação nos valores de pectina total durante o desenvolvimento da gabiroba e aumento marcante da pectina solúvel entre 48 e 53 dias, intervalo este coincidente 


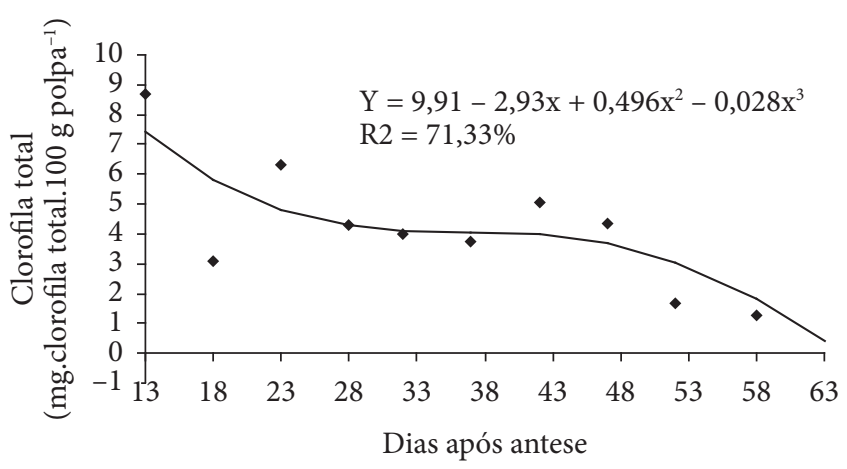

Figura 6. Valores de clorofila total durante os estádios de desenvolvimento em frutos de gabiroba.
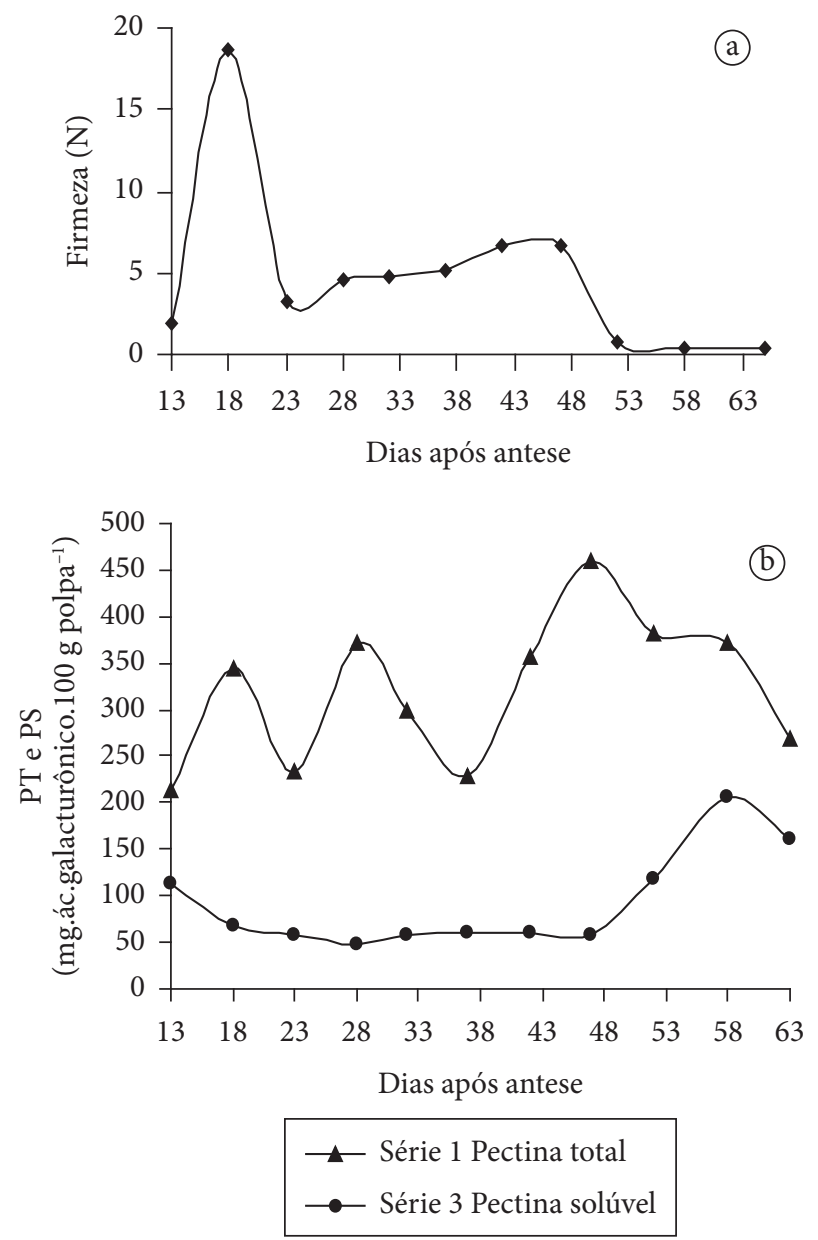

Figura 7. a, b) Valores para firmeza, pectina total e pectina solúvel, durante o desenvolvimento dos frutos de gabiroba.

com o amaciamento do fruto (Figura 7b). Esta queda de firmeza pode ser relacionada com a despolimerização péctica na parede celular, que culmina com a solubilização das pectinas durante o seu amadurecimento, pela ação de enzimas hidrolíticas. Segundo Vilas Boas (1999), a diminuição da firmeza pode estar relacionada principalmente, com a perda de integridade da parede celular, atribuída à ação de enzimas pectinolíticas principalmente.

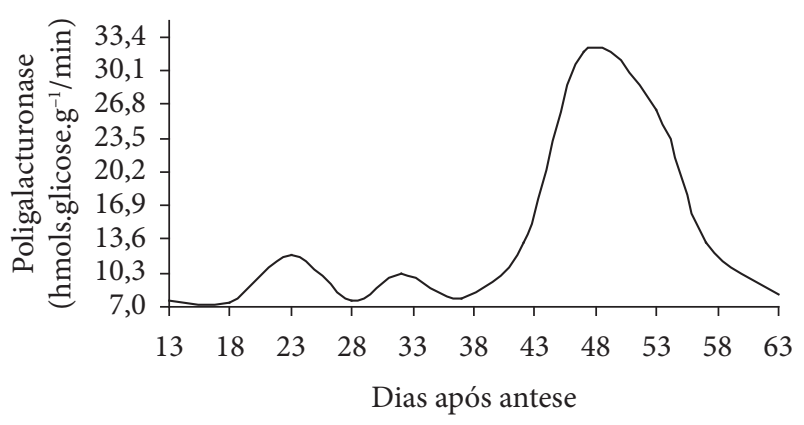

Figura 8. Valores da atividade da poligalacturonase durante o desenvolvimento da gabiroba.

Dentre as enzimas pectinolíticas de maior importância no amaciamento de frutos, a pectinametilesterase (PME) assume um dos principais papéis, por promover a desmetoxilação dos polímeros de pectina, favorecendo a atuação da poligalacturonase, que quebra os polímeros pécticos em unidades de ácidos galacturônicos que irão compor a pectina solúvel.

Não obstante, não foi observada a atividade da PME durante o desenvolvimento da gabiroba. Santos et al. (2005), Vilas Boas (2003) e Carvalho e Lima (2002) também não observaram atuação dessa enzima em abacaxi, mangas e kiwis minimamente processados, creditando a ausência ao estádio avançado de maturação dos frutos, embora a gabiroba tenha sido analisada ao longo de todo seu desenvolvimento.

A atividade da poligalacturonase foi observada em gabiroba. Uma marcante elevação na atividade desta enzima foi observada entre o $38^{\circ}$ e $43^{\circ}$ dia, com o pico de atividade ocorrendo no $48^{\circ}$ dia de desenvolvimento (Figura 8), coincidente como o pico climatérico de respiração. O maior índice de pectina solúvel e perda da firmeza entre 48 e 53 dias de desenvolvimento pode ser relacionado ao incremento na atividade da PG no fruto, induzindo o seu amaciamento. Vilas Boas (2003) reporta também uma relação entre a atividade da PG na degradação de pectinas, devido ao acréscimo de pectina solúvel e o amaciamento, em mangas minimamente processadas.

\section{Conclusões}

A floração inicia-se no mês de agosto e a frutificação em setembro, no município de Lavras, sul do Estado de Minas Gerais.

O estádio de desenvolvimento (abertura da for até o amadurecimento) da gabiroba compreende um período de 63 dias (9 semanas).

O aumento da massa e dos diâmetros longitudinal e transversal da gabiroba ao longo do seu estádio de desenvolvimento caracterizam um padrão sigmoidal simples de crescimento do fruto.

Gabirobas apresentaram um comportamento respiratório típico de frutos climatéricos. 
Acentuado metabolismo do fruto marcado pela elevação na atividade respiratória, sólidos solúveis, $\mathrm{pH}$, pectina solúvel e atividade de poligalacturonase, redução da acidez titulável e firmeza e alterações associadas à coloração por volta do $43^{\circ}$ dia, caracterizam o amadurecimento da gabiroba.

\section{Referências bibliográficas}

ALMEIDA, S. P. et al. Cerrado: espécies vegetais úteis. Planaltina: Embrapa/CPAC, 1998. 464 p.

CHITARRA, M. I. F. Processamento mínimo de frutas e hortaliças. Lavras: UFLA/FAEPE, 2000. 113 p. Apostila.

CHITARRA, M. I. F. Processamento mínimo de frutas e hortaliças. Viçosa: Centro de produções técnicas, 1998. 88 p.

Chitarra, M. I. F.; CHITARRA, A. B. Pós-colheita de Frutos e Hortaliças. Fisiologia e Manuseio. 2 ed. Lavras: FAEPE, 2005.

CHITARRA, M. I. F.; CHITARRA, A. B. Pós-colheita de Frutos e Hortaliças: glossário. Lavras: Editora UFLA, 2006.

Chitarra, M. I. F.; CHITARrA, A. B. Pós-colheita de frutos e hortaliças: fisiologia e manuseio. Lavras: ESAL, Fundação de Apoio, Pesquisa e Extensão ao Ensino, 1990. 293 p.

FERREIRA, D. F. Análises estatísticas por meio do SISVAR para windows versão 4.0. In: REUNIÃO ANUAL DA REGIÃO BRASILEIRA DA SOCIEDADE INTERNACIONAL DE BIOMETRIA, 45, 2000, São Carlos. Resumos... São Carlos: UFSCar, 2000. p. 235.
FONSECA, C. E. L.; MUNIZ, I A. F. Informações sobre a cultura de espécies frutíferas nativas da região dos cerrados. Informe Agropecuário, v. 16, n. 173, p. 2-16, Mar./Abr. 1992.

MARTINS, L. P. et al. Desenvolvimentos de ciriguela (Spondias purpúrea). Revista Brasileira de Fruticultura, v. 25, n. 1, p. 11-14, 2003.

MOURA, M. L. et al. Crescimento e desenvolvimento de frutos do tomateiro 'Santa Clara' e do seu mutante natural 'firme'. Ciência e Agrotecnologia, v. 28, n. 6, p. 1284-1290, Nov./Dez. 2004.

RODRIGUES, L. J. O pequi (Caryocar brasiliense Camb.): ciclo vital e agregação de valor pelo processamento mínimo. Lavras, 2005. 152 p. Dissertação (Mestrado em Ciência dos Alimentos) - Universidade Federal de Lavras.

SANTOS, J. C. B. et al. Avaliação da qualidade de abacaxi 'Pérola' minimamente processado armazenado sob atmosfera modificada. Ciência e Agrotecnologia, v. 29, n. 2, p. 353-361, Mar./Abr. 2005.

VILAS BOAS, B. M. Aplicação da qualidade de mangas 'Tommy Atkins' minimamente processadas e tratadas quimicamente. Lavras, 2003. 89 p. Dissertação (Mestrado em Ciência dos Alimentos) - Universidade Federal de Lavras.

VILAS BOAS, E. V. de B. Aspectos fisiológicos do desenvolvimento de frutos. Lavras: UFLA, Fundação de Apoio, Pesquisa e Extensão ao Ensino, 1999. 75 p.

VILAS BOAS, E. V. B. Modificações pós-colheita de banana 'Prata' (Musa acuminata $\times$ Musa balbisiana grupo AAB) g-irradiada. 1995. 73p. Dissertação (Mestrado em Ciência dos Alimentos) Universidade Federal de Lavras, Lavras, MG. 